\title{
EDITORIAL
}

For reprint orders, please contact: reprints@futuremedicine.com

\section{The potential detrimental effect of corticosteroids in prostate cancer}
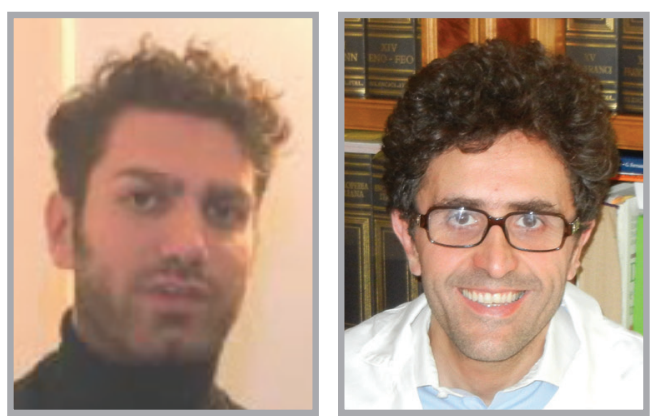

Pasquale Rescigno ${ }^{1}$ \& Giuseppe di Lorenzo*,

\author{
“...corticosteroids should be used \\ carefully in men with prostate cancer \\ who have been treated with \\ androgen deprivation therapy on a \\ long-term basis...”
}

Diagnosis of prostate cancer (PC) at local or regional stages is associated with an excellent prognosis [1]; however, patients with metastatic PC generally achieve only temporary disease control with hormonal therapy and they eventually develop disease progression despite castrate serum androgen levels. In the last years the number of drugs available for metastatic castration-resistant prostatic cancer (mCRPC), such as abiraterone, cabazitaxel, enzalutamide and sipuleucel-T, has rapidly increased [2]. Some of them, such as the classic chemotherapeutic docetaxel, require the concomitant use of corticosteroids. The large use of corticosteroids should lead physicians to question themselves regarding the long-term use of glucocorticoids and their role in PC and especially in advanced disease.

Corticosteroids are commonly used in the treatment of cancer due to their antiinflammatory activities, and they have a direct effect on tumor-induced pain, secondary to bone metastases [3]. Thus, corticosteroids are used both to manage tumor-related symptoms and to counteract toxic effects and side effects associated with prostatic anticancer drugs; they delay the onset of fluid retention induced by docetaxel [4] and they can also help to prevent the mineralocorticoid syndrome secondary at abiraterone acetate administration [5].

However, their use is not without disadvantages. The most common adverse events related to corticosteroids use are edema, hypertension, weight gain, hyperglycemia/steroid-induced diabetes, posterior subcapsular cataracts and glaucoma [6]. These toxicities depend on exposure time and total doses [7].

Furthermore, corticosteroids should be used carefully in men with PC who have been treated with androgen deprivation therapy on a long-term basis, as they could exacerbate cardiovascular risk and metabolic dysfunctions correlated with androgen deprivation therapy [8].

Recently, the androgen receptor (AR) and AR-regulated genes have been studied to be active in CRPC, despite undetectable levels of testosterone in the blood [9]. Nelson defined four states of PC based on sources of androgenic ligands and the activity of AR [10]. According to this theory, in third state, PC cells are androgen ligand independent and AR dependent. In

\section{KEYWORDS}

- corticosteroids $\bullet$ prostate cancer

- sequential therapy • side effects

'Genitourinary Cancer Section, Medical Oncology, Department of Clinical Medicine, Federico II University, Napoli, Italy *Author for correspondence: Tel.: +39 081 746 3660; Fax: +39 081220 3147; giuseppedilorenzoncol@hotmail.com 


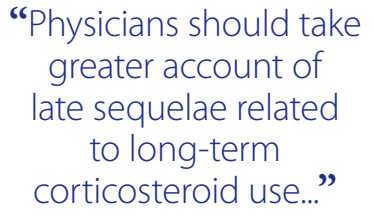

"Physicians should take greater account of to long-term corticosteroid use...” this state, the AR remains active in the absence of ligands through cross-talk with other signal transduction pathways, thus corticosteroids could play a role in AR activation [10]. Preclinical evidence have enforced this theory [11] and recent studies on abiraterone acetate explain the early progression through to the promiscuous activation of $A R$ by steroid metabolites such as glucocorticoids [12].

Richards and colleagues show that mutant L701H T877A AR is activated by exogenous glucocorticoids administered with abiraterone. Combining abiraterone with enzalutamide or increasing abiraterone doses could avoid AR promiscuous activation [13]. If this has been evaluated in preclinical studies, more confirmations to these theories come from post hoc analyses of two Phase III randomized and controlled trials on second-line therapies for mCRPC.

The AFFIRM trial demonstrated the efficacy of enzalutamide, an irreversible AR inhibitor, as a second-line therapy in $\mathrm{mCRPC}$ after docetaxel failure [14]. Analyzing demographic characteristics of the AFFIRM population, patients who received corticosteroids were generally sicker and had more advanced disease. In multivariate analysis of baseline prognostic factors, the corticosteroid use was associated with reduced survival and adverse side effects, such as the presence of visceral metastases and anemia.

Moreover, although enzalutamide showed its efficacy compared with placebo in both the noncorticosteroid- and corticosteroid-treated groups, overall survival, radiologic progressionfree survival and prostate-specific antigen progression were all inferior in the corticosteroidtreated group. With regard to toxicity, patients on corticosteroids had higher rates of grade 3-4 adverse events compared with no corticosteroid patients (63.3 vs 34.4\%, respectively) [15].

Similarly, in the COUAA-301 trial, which evaluated the efficacy of abiraterone after docetaxel in mCRPC [16], the role of corticosteroids at baseline was studied. Corticosteroids at baseline included prednisone, dexamethasone and other corticosteroids $(n=489)$, while 797 patients were not treated with corticosteroids. In this study, corticosteroids at baseline was not a strong independent prognostic factor in mCRPC postdocetaxel treatment, but was associated with worse baseline disease characteristics and inferior overall survival [17].

At present, we have medical options that do not need the additional use of steroids such as enzalutamide or alpharadin. As previously stated, enzalutamide demonstrated the efficacy as a second-line therapy in CRPC in the AFFIRM trial [14]. This Phase III trial randomized 1199 men with mCRPC following chemotherapy to enzalutamide (160 mg/day) or placebo in a $2: 1$ ratio. Overall survival favored enzalutamide (median: 18.4 vs 13.6 months; hazard ratio for death: 0.63 ; 95\% CI: 0.53-0.75; p < 0.001), which led to regulatory approval. Treatment was well tolerated and toxicities included fatigue, diarrhea and hot flashes. Seizures were reported in five patients $(0.6 \%)$ receiving enzalutamide, which was expected on the grounds of previous preclinical and clinical experience, and may warrant caution when the drug is administered to patients with a history of epilepsy. Retrospective analysis from the AFFIRM trial shows that enzalutamide is active in patients with low burden disease, while it could be ineffective in the presence of multiple metastases and in highly pretreated patients [14].

Alpharadin is a calcium-mimetic radiopharmaceutical that accumulates in bones and emits $\alpha$-radiation from radium-223 decay and releases relatively high energy with a narrow range (2-10 cells). Following promising results in a Phase II trial, the Phase III ALSYMPCA trial was conducted in $\mathrm{mCRPC}$ patients with symptomatic bone metastases, who either had received or were ineligible for docetaxel. Patients received six doses of alpharadin $50 \mathrm{kBq} / \mathrm{kg}$ intravenously every 4 weeks.

At the interim analysis, which involved 809 patients, radium-223, as compared with placebo, significantly improved overall survival (median: 14.0 vs 11.2 months; hazard ratio: $0.70 ; \mathrm{p}=0.002)$. The updated analysis involving 921 patients confirmed the radium-223 survival benefit (median: 14.9 vs 11.3 months; hazard ratio: $0.70 ; \mathrm{p}<0.001$ ). Assessments of all main secondary efficacy end points also showed a benefit of radium-233 compared with placebo. Radium-223 was associated with low myelosuppression rates and fewer adverse events [18]. However radium-233 is effective only in patients with bone metastases and cannot be used in visceral or lymph node disease.

Treatment options for CRPC patients have greatly increased in recent years and several active agents can be offered to our patients [19]. To date, there are no randomized trials comparing these agents and no predictive models or biomarkers are able to identify patients who 
are likely to benefit from any of these drugs. Therefore, the choice of therapy is based on clinical expertise. Physicians should take greater account of late sequelae related to long-term corticosteroid use; a patient history should be collected and corticosteroids should be managed carefully in diabetic, hypertensive or obese patients, weighing the pros and cons of their use. Chemotherapeutic agents that require concomitant use of corticosteroids should be avoided, or it proposal of eliminating concomitant steroid use or other available medical options that do

\section{References}

1 Giannarini G, Autorino R, Valent F et al. Combination of perianalintrarectallidocaine-prilocaine cream and periprostatic nerve block for pain controlduring transrectal ultrasound guided prostate biopsy: a randomized, controlledtrial. J. Urol. 181, 585-591 (2009).

2 Rescigno P, Buonerba C, Bellmunt J, Sonpavde G, De Placido S, Di Lorenzo G. New perspectives in the therapy of castration resistant prostate cancer. Curr. Drug Targets 13(13), 1676-1686 (2012).

3 Lussier D, Huskey AG, Portenoy RK. Adjuvant analgesics in cancer pain management. Oncologist 9, 571-591 (2004).

4 Piccart MJ, Klijn J, Paridaens R et al. Corticosteroids significantly delay the onset of docetaxel-induced fluid retention: final results of a randomized study of the European Organization for Research and Treatment of Cancer Investigational Drug Branch for Breast Cancer. J. Clin. Oncol. 15(9), 3149-3155 (1997).

5 Attard G, Reid AHM, Auchus RJ et al. Clinical and biochemical consequences of CYP17A1 inhibition with abiraterone given with and without exogenous glucocorticoids in castrate men with advanced prostate cancer. J. Clin. Endocrinol. Metab. 97(2), 507-516 (2012).

6 Hougardy DM, Peterson GM, Bleasel MD, Randall CT. Is enough attention being given to the adverse effects of corticosteroid

not require the additional use of steroids, should be preferred.

\section{Financial \& competing interests disclosure}

The authors have no relevant affliations or financial involvement with any organization or entity with a financial interest in or financial conflict with the subject matter or materials discussed in the manuscript. This includes employment, consultancies, honoraria, stock ownership or options, expert testimony, grants or patents received or pending, or royalties.

No writing assistance was utilized in the production of this manuscript.

therapy? J. Clin. Pharm. Ther. 25(3), 227-234 (2000).

7 Dorff TB, Crawford ED. Management and challenges of corticosteroid therapy in men with metastatic castrate-resistant prostate cancer. Ann. Oncol. 24, 31-38 (2013).

8 Saylor PJ, Smith MR. Adverse effects of androgen deprivation therapy: defining the problem and promoting health among men with prostate cancer. J. Natl Compr. Canc. Netw. 8, 211-223 (2010).

9 Montgomery RB, Mostaghel EA, Vessella R et al. Maintenance of intratumoral androgens in metastatic prostate cancer: a mechanism for castration-resistant tumor growth. Cancer Res. 68, 4447-4454 (2008).

10 Nelson PS. Molecular states underlying androgen receptor activation: a framework for therapeutics targeting androgen signaling in prostate cancer. J. Clin. Oncol. 30(6), 644-646 (2012).

11 Zhao XY, Malloy PJ, Krishnan AV et al. Glucocorticoids can promote androgenindependent growth of prostate cancer cells through a mutated androgen receptor. Nat. Med. 6, 703-706 (2000).

12 Ferraldeschi R, Sharifi N, Auchus RJ, Attard G. Molecular pathways: inhibiting steroid biosynthesis in prostate cancer. Clin. Cancer Res. 19(13), 3353-3359 (2013).

13 Richards J, Lim AC, Hay CW et al. Interactions of abiraterone, eplerenone, and prednisolone with wild-type and mutant androgen receptor: a rationale for increasing abiraterone exposure or combining with
MDV3100. Cancer Res. 72(9), 2176-2182 (2012).

14 Scher HI, Fizazi K, Saad F et al.; AFFIRM Investigators. Increased survival with enzalutamide in prostate cancer after chemotherapy. N. Engl. J. Med. 367(13), 1187-1197 (2012).

15 Scher H I, Fizazi K, Saad F et al. Impact of on-study corticosteroid use on efficacy and safety in the Phase III AFFIRM study of enzalutamide (ENZA), an androgen receptor inhibitor. Presented at: American Society Clinical Oncology (ASCO), Genitourinary Cancers Symposium. Orlando, FL, USA, 14-16 February (2013).

16 de Bono JS, Logothetis CJ, Molina A et al.; COU-AA-301 Investigators. Abiraterone and increased survival in metastatic prostate cancer. N. Engl. J. Med. 364(21), 1995-2005 (2011).

17 Montgomery RB, Kheoh TS, Molina A et al. Effect of corticosteroid (CS) use at baseline (CUB) on overall survival (OS) in patients receiving abiraterone acetate $(\mathrm{AA})$ : results from a randomized study (COU-AA-301) in metastatic castration-resistant prostate cancer (mCRPC) post-docetaxel (D). Presented at: ASCO Annual Meeting. Chicago, IL, USA, 31 May-4 June 2013.

18 Parker C, Nilsson S, Heinrich D et al. Alpha emitter radium-223 and survival in metastatic prostate cancer. N. Engl. J. Med. 369(3), 213-223 (2013).

19 Di Lorenzo G, Buonerba C, Kantoff PW. Immunotherapy for the treatment of prostate cancer. Nat. Rev. Clin. Oncol. 8, 551-561 (2011). 